\title{
Práticas corporais e desinstitucionalização em saúde mental: Desafios e possibilidades
}

Ana Karenina de Melo Arraes Amorim. Universidade Federal do Rio Grande do Norte.

Maria Aparecida Dias. Universidade Federal do Rio Grande do Norte.

Mackson Luiz Fernandes da Costa. Instituto Federal do Rio Grande do Norte.

Allana de Carvalho Araújo. Universidade Federal do Rio Grande do Norte.

Deyze da Silva Ferreira. Universidade Federal do Rio Grande do Norte.

\section{Resumo}

O presente artigo trata do recorte de uma pesquisa que objetivou investigar as práticas voltadas para o processo de desinstitucionalização realizadas em um hospital psiquiátrico de uma cidade do nordeste brasileiro, focalizando no corpo e nas práticas corporais como recurso. Para tanto, foram realizadas 30 entrevistas e 07 oficinas de práticas corporais com profissionais envolvidos e foram analisadas como essas práticas corporais poderiam contribuir para o trabalho de desinstitucionalização dos moradores do hospital. Como resultados, evidencia-se e discute-se a importância de que sejam realizadas atividades intra e extramuros do hospital que considerem as marcas da institucionalização nos corpos, tanto dos moradores, como dos profissionais que os acompanham, de modo a potencializar a desinstitucionalização em sentido amplo e a construção da autonomia dos atores envolvidos e do cuidado em liberdade.

Palavras-chave: corpo; desinstitucionalização; saúde mental; hospital psiquiátrico.

\begin{abstract}
Body practices and deinstitutionalization in mental health: Challenges and possibilities. This article deals with the part of a research that investigated the practices aimed at the deinstitutionalization process held in a psychiatric hospital of a city in northeastern Brazil, focusing on the body and bodily practices as a resource. Therefore, we carried out 30 interviews and 07 workshops of corporal practices with professionals involved and it was analyzed how these bodily practices could contribute to the deinstitutionalization work with the hospital residents. As a result, it is evident and discusses the importance of intra and extramural activities of the hospital be held to consider the trademarks of institutionalization in the bodies of both the residents and the professionals who assist them, so enhance the deinstitutionalization broadly and the construction of autonomy of the actors involved and care free.
\end{abstract}

Keywords: body; deinstitutionalization; mental health; psychiatric hospital.

\section{Resumen}

Prácticas corporales y la desinstitucionalización en salud mental: Retos y possibilidades. Este artículo se ocupa de la parte de una pesquisa que investigó las prácticas dirigidas a el proceso de desinstitucionalización que tuvo lugar en un hospital psiquiátrico de una ciudad en el nordeste de Brasil, centrado en el cuerpo y las prácticas corporales como recurso. Por lo tanto, llevamos a cabo 30 entrevistas y 07 talleres de prácticas corporales con los profesionales implicados y fueron analizadas como estas prácticas corporales podrían contribuir a el labor de desinstitucionalización de los residentes del hospital. Como resultado, es evidente y se analiza la importancia de las actividades intra y extramuros del hospital se celebrará para considerar las marcas registradas de institucionalización en los cuerpos de los residentes y de los profesionales que los asisten, con el fin de mejorar la desinstitucionalización en amplio sentido y la construcción de la autonomía de los actores involucrados y del cuidado en liberdad.

Palabras clave: cuerpo; desinstitucionalización; salud mental; hospital psiquiátrico. 
A Reforma Psiquiátrica surge de modo a criticar e confrontar o modelo clássico do paradigma da Psiquiatria, perpassando não só transformações de caráter técnico, mas também teórico, político, cultural e social. Firmada legalmente no Brasil por meio da Lei n. 10.216, de 2001, propõe uma reformulação no modelo assistencial em saúde mental em que se busca uma política mais social que sanitária (Ministério da Saúde, 2004). Para tanto, faz-se necessária a desconstrução de uma cultura que é majoritária: a que sustenta a violência, a segregação e o aprisionamento da loucura.

Entretanto, para destruir ou edificar uma cultura, é preciso a desconstrução e construção de outras tantas que a sustentem ou a confrontem. $A$ invenção de novas realidades na saúde mental, então, como apontam Rotelli, Leonardis e Mauri (2001) e Amarante (2007), enfrenta o desafio de desmontar toda a estrutura manicomial que tradicionalmente separou a doença da existência global e complexa da pessoa, segregando também, dessa maneira, o doente do corpo social. Esse processo, denominado desinstitucionalização, não se traduz em desassistência, nem se resume à desospitalização, mas traz consigo um caráter prático de reconstrução permanente de saberes, discursos e ações no intuito de que novas formas de vida sejam pensadas e se tornem possíveis.

Uma maneira de se trabalhar nesse sentido é prezar por iniciativas que apostem na circulação da loucura na vida social, de modo que se criem novas formas de se relacionar a partir da reabilitação psicossocial e da inserção social, garantindo o exercício da cidadania e a viabilização de projetos de vida (Amorim \& Dimenstein, 2009; Salles \& Miranda, 2016).

Um desafio a essa proposta consiste no processo de desinstitucionalização das pessoas que residem nos hospitais psiquiátricos há longo tempo, visto que, desligados da realidade fora dos muros do manicômio e sob efeito da institucionalização, a reinserção social e a reabilitação psicossocial requerem cuidados específicos, sobretudo no que se refere a construção de novas sociabilidades (Moreira \& Castro-Silva, 2011). As dificuldades estão tanto nas limitações corporais dessas pessoas - em decorrência dos muitos anos de vida voltados à instituição e fortemente submetidos à medicalização -, quanto no encontro da sociedade com corpos não habituados a corresponder a alguns dos parâmetros de normalidade adotados por ela. Segundo pesquisas realizadas (Medeiros \& Guimarães, 2002; Salles \& Miranda, 2016), essas pessoas sofrem com o estigma por serem pacientes psiquiátricos na sociedade que, a partir de uma lógica racionalista, constrói projeções acerca da loucura em que se subtrai dos "anormais" a condição de cidadania, prerrogativa apenas para os "ajustados".

No estado do nordeste brasileiro onde foi realizado o estudo, o número de residentes de longa permanência é significativo. Existiam, até o momento da pesquisa, após a inauguração de dois Serviços Residenciais Terapêuticos na capital do estado, aproximadamente 12 (doze) internos no maior hospital psiquiátrico público da capital - onde realizou-se o campo prático da presente pesquisa, além daqueles que residem em outras estruturas hospitalares e cuja condição de morador não é oficialmente notificada.

De acordo com Gonçalves, Fagundes, Lovisi e Lima (2001), as instituições hospitalares brasileiras, em sua maioria, não oferecem aos pacientes programas específicos dirigidos à reabilitação psicossocial, assim como não dispõem de condições adequadas que garantam o respeito à individualidade e o direito ao exercício de um convívio social digno. Nesse contexto, os residentes sofrem com o empobrecimento da motricidade, principalmente, devido à prolongada permanência sob a égide das práticas institucionais biopolíticas, que enrijecem seus corpos e esmaecem seus vínculos sociais e sua autonomia, negando-Ihes o direito de circular pela cidade e gerenciar suas próprias vidas (Amorim \& Dimenstein, 2009; Salles \& Miranda, 2016).

O corpo presente na instituição pautada no paradigma tradicional da Psiquiatria se encontra moldado às ações da instituição, tornando-se dominado por ela. Esse domínio ocorre em todas as suas peculiaridades, no âmbito do corpo como produtor de ações individuais e nas relações como produtor social, visto que o corpo não é apenas um objeto que garante a existência humana, mas constitui o próprio ser em vida e como história (Costa, 2011; Sant'Anna, 1995).

Nessa perspectiva, compreende-se que o modo como se entende o corpo afetará diretamente as relações de poder na instituição. Quando ele é entendido como um objeto que é acometido por uma doença com sintomas clinicamente comprovados, teremos uma relação médico-paciente que se baseará no tratamento da patologia, por meio de fármacos que buscam o controle dos sintomas para que o corpo retorne a um padrão aceito como saudável. Esse tipo de relação torna o paciente dependente da instituição, submetendo sua própria vontade às normas desta, visto que se trata de "um encontro entre um sujeito e um corpo ao qual 
não é dada outra alternativa exceto a de converter-se em objeto aos olhos de quem o examina" (Basaglia, $1967 / 2005$, p. 74). Mas a partir do momento que o corpo for entendido como espaço de subjetividade, como produtor cultural, que se comunica com o sensível, são possíveis relações e práticas voltadas para "a existência-sofrimento dos pacientes e sua relação com o corpo social" (Rotelli et al., 2001, p. 90).

A ideia de corpo com que se trabalha aqui está perpassada pela noção de autonomia que o sujeito, dentro da sua condição, seja ela qual for, possa exercer. Acreditamos, como Rodrigues (2008), que o indivíduo, à medida que produz seu corpo, produz também novas formas de subjetivação, de modo que associa a representação que faz de seu corpo à consciência que dele tem. Assim, a motricidade apresenta-se como meio de colocar o sujeito no mundo e possibilitar descobertas e transformações, bem como de aprofundar a consciência de si, na medida em que permitem "fazer existir o corpo para si próprio, reconquistar sua interioridade" (Rodrigues, 2008, p. 159).

Nesse sentido, as práticas corporais tornam-se possíveis estratégias de promoção da desinstitucionalização. Pensando em práticas de reabilitação psicossocial com pessoas que residem desde longo tempo em hospitais psiquiátricos, entende-se aqui que o trabalho com a motricidade possa colocar esses sujeitos em contato consigo mesmo através da descoberta do seu corpo, da sua motricidade, não mais impregnada de medicação. Práticas que devolvam ao praticante sua energia de vida, capturada, não só pela sua condição institucional e clínica, como também, pelo que o universo social ao qual pertence.

Da mesma forma, é fundamental considerar que os profissionais cuidadores desses residentes no hospital também estão sob efeito da institucionalização, visto que toda organização inclui, além de uma disciplina de atividades, "uma disciplina de ser - uma obrigação de ser um determinado caráter e morar em determinado mundo" (Goffman, 2008, p. 159). Assim, o trabalho com a motricidade dos próprios cuidadores também tem potencial de transformar olhares e proporcionar descobertas e criações, podendo produzir resultados no sentido da desinstitucionalização já no âmbito das práticas dos técnicos dos hospitais psiquiátricos.

Tendo em vista o que fora exposto, o presente estudo visou investigar as práticas voltadas para a desinstitucionalização realizadas em um hospital psiquiátrico da capital de um estado do Nordeste brasileiro, acrescentando a elas o desenvolvimento de oficinas corporais junto aos técnicos dessa instituição e discutindo como essas práticas corporais podem contribuir para a desinstitucionalização.

\section{Metodologia}

Considerando a natureza do objeto de estudo em questão, a problemática que se delimita em torno dele e os fundamentos teóricos apresentados, a proposta metodológica deve estar calcada nos princípios de uma pesquisa qualitativa que toma a categoria da subjetividade como pressuposto epistemológico fundamental nos diferentes níveis de construção da investigação. Nesse sentido, desenvolveu-se o delineamento do estudo etnográfico e seu aparato instrumental no encontro dos pesquisadores com a realidade estudada, e esse desenho serviu de mediador e facilitador na construção de conhecimentos. O contexto interativo e o contexto relacional da pesquisa determinaram o valor da qualidade da informação, o qual só se pôde conseguir com o envolvimento e a motivação dos sujeitos estudados (González-Rey, 2002, p. 58).

Por isso, tomamos por base a perspectiva etnográfica segundo a qual os processos de construções teóricas, coleta de dados e registro se dão ao mesmo tempo, sendo um processo que envolve e exige sensibilidade reflexiva (Caprara \& Landim, 2008).

Assim, considerando este posicionamento acerca do método, podemos aqui apresentar em linhas gerais a perspectiva que sustenta esta proposta e, baseado nela, apontar os procedimentos possíveis para a investigação.

Nas intervenções realizadas, pretendemos transcender as intenções meramente acadêmicas, entendendo que seja papel do pesquisador "contribuir efetivamente com os problemas de um coletivo pesquisado, ou seja, sua capacidade de dispor de instrumentos teórico-metodológicos em prol dos objetivos existentes no grupo sob o qual sua ação vai-se debruçar" (Paulon, 2005, p. 20). Para tanto, elegemos como procedimentos metodológicos: observações participantes, entrevistas semiestruturadas e oficinas corporais.

A pesquisa cumpriu as exigências éticas estabelecidas para a pesquisa no Brasil por meio da Resolução CNS n. 466/2012, considerando as peculiaridades das investigações em ciências humanas.

A pesquisa de campo foi realizada em duas etapas. A primeira etapa foi realizada por meio da observação participante, em um hospital psiquiátrico público 
de uma capital nordestina, do cotidiano do grupo de moradores de longa permanência e do trabalho dos profissionais responsáveis pelo cuidado a essas pessoas. Participamos de reuniões com a equipe e com o grupo de moradores, de modo a acompanhar o andamento do processo e identificar as principais dificuldades na desinstitucionalização. Além disso, realizamos entrevistas semiestruturadas com os profissionais, com perguntas abertas sobre as características principais do grupo de moradores e as atividades desenvolvidas junto a eles.

Na segunda etapa, a partir dos dados já produzidos, elaboramos e realizamos, com os profissionais envolvidos no processo de desinstitucionalização dos moradores, oficinas corporais semanais, com duração de uma hora, utilizando-nos de técnicas de expressão corporal, jogos cooperativos, jogos teatrais, atividades lúdicas, dança, atividades rítmicas que resgatem a cultura corporal do grupo e relaxamento. Ou seja, foram propostas atividades que estimulem e considerem o entrelaçamento entre corpo, natureza e cultura, ligando práticas, modos de ser, de fazer e de viver as diferentes realidades sociais e históricas das pessoas envolvidas (Mendes \& Nóbrega, 2009). No total, foram realizadas, entre agosto e dezembro de 2011, sete oficinas, tendo participado, de cada encontro, uma média de seis profissionais.

Utilizou-se como forma de registro dos dados o diário de campo nas duas etapas de pesquisa (diários das observações e das oficinas) e a gravação em áudio das entrevistas (mediante autorização dos entrevistados) e posterior transcrição.

A análise dos dados foi feita com base nos conteúdos dos registros dos diários de campo e das entrevistas a partir da proposta de Bardin (2004). Os dados foram organizados em categorias relacionadas ao problema de pesquisa que permitiram a discussão realizada.

Ressalta-se que o presente trabalho é um recorte de uma pesquisa na qual ainda pretendemos realizar intervenções e entrevistas semiestruturadas com os moradores envolvidos no processo de desinstitucionalização sobre o modo como estão vivendo a experiência, as expectativas que ela produz e os efeitos das práticas corporais na vida deles. Do mesmo modo, conforme se pensou inicialmente, as oficinas corporais também serão realizadas junto aos moradores do hospital. Contudo, aqui nos restringimos a tratar apenas no trabalho realizado junto aos profissionais.

Entendendo que a desinstitucionalização dos moradores de longa permanência perpassa a prática, o saber e as relações existentes dentro do hospital, vimos que, antes de iniciarmos intervenções voltadas especificamente para essas pessoas, fazia-se necessário cuidar dos cuidadores, convidando-os a discutir e a refletir sobre as ideias que motivaram o desenvolvimento deste trabalho.

\section{Resultados}

\section{Caracterização do Espaço Físico do Hospital}

No período em que nos inserimos no campo, o hospital psiquiátrico atendia um total de 120 internos, sendo 80 do sexo masculino e 40 do sexo feminino. As enfermarias do hospital eram separadas por sexo e apresentavam distinções consideráveis quanto ao modo de organização do ambiente e em termos de comunicação entre os profissionais de cada equipe e entre as equipes e os moradores.

A enfermaria feminina destinava-se tanto para as usuárias residentes de longa permanência no hospital, como também para as que passam pouco tempo na condição de internas e para as que ficam em caráter rotativo. Contrariamente, as enfermarias masculinas eram distintas entre o primeiro e os outros dois grupos, sendo, portanto, espaços físicos menores. Dessa forma, a organização no interior de cada enfermaria ocorria também de forma diferenciada: enquanto na feminina todos os quartos eram coletivos, na masculina havia um deles para um ou dois moradores de longa permanência.

Quanto ao contato entre a equipe profissional e os moradores, havia uma reunião semanalmente na enfermaria masculina com a finalidade de discutir assuntos relacionados ao cotidiano do hospital. Embora esse encontro fosse destinado aos técnicos, também os moradores podiam participar opinando e sugerindo. $\mathrm{Na}$ enfermaria feminina, por sua vez, não havia reuniões conjuntas entre profissionais e moradoras.

\section{Realização das entrevistas}

Entrevistamos 30 profissionais de nível superior e médio de um hospital psiquiátrico público (de um total de 200 profissionais entre os 458 funcionários do hospital), que trabalham diretamente com os moradores de longa permanência da instituição, ou seja, são profissionais médicos, enfermeiros, psicólogos, assistentes sociais, terapeutas ocupacionais e técnicos de enfermagem que são responsáveis pelo cuidado aos moradores. Dos entrevistados, 15 atuam em enfermaria feminina, oito em enfermaria masculina e sete em 
ambos os locais. Dessa forma, nos resultados abaixo se considera 22 entrevistados que trabalham com moradoras do sexo feminino e 15 com moradores do sexo masculino. Apesar do maior numero de internos ser do sexo masculino, o numero de profissionais para cada enfermaria não se diferencia, o que pode justificar a menor disponibilidade em ceder entrevistas dos profissionais que trabalham na enfermaria masculina por sobrecarga de trabalho.

Quando solicitados a caracterizar um perfil do grupo com que trabalhavam, os profissionais da equipe feminina disseram que as residentes são idosas; dependentes e não autônomas; interagem pouco entre si e com a equipe; perderam totalmente o vínculo com a família ou possuem este vinculo bastante fragilizado; apresentam autocuidado comprometido, necessitando de auxílio na alimentação e higienização; participam pouco de atividades propostas no hospital e não têm iniciativa para buscar ou propor novas atividades.

Os homens, por sua vez, foram caracterizados como sendo um grupo que interage com a equipe e com os outros internos; que estão em processo de resgate da autonomia mesmo que ainda sendo marcadamente dependentes dos profissionais; e que também possuem vínculos fragilizados ou rompidos com suas famílias. Além disso, foi relatado que três dos homens estavam em processo efetivo de saída do hospital, por meio de um processo de alta assistida.

No tocante ao trabalho exercido por cada profissional no hospital, oito dos entrevistados da ala feminina e três da ala masculina afirmaram explicitamente não participar de atividades dentro ou fora do hospital que não fossem as específicas de seu cargo profissional. Nessa mesma ordem, quatro e oito disseram participar de atividades tanto intra como extramuros, além de seus trabalhos específicos. Dos que afirmaram participação apenas em trabalhos dentro do hospital, o numero de entrevistados foi de quatro para cada ala.

Buscou-se também conhecer o que os profissionais achavam dessas atividades e que efeitos acreditavam que elas tinham na vida dos moradores do hospital. A maior parte dos entrevistados - 16 da ala feminina e 13 da masculina - disse perceber que os residentes mudam o comportamento após essas atividades, de forma considerada positiva - exemplo do que fora dito é o tornar-se mais receptivo ao contato com outras pessoas, o mostrar-se mais comunicativo, com melhor humor, demonstrar autonomia, pedir para sair novamente. Além disso, nove profissionais da ala feminina e nove da masculina avaliam as atividades fora do hospital como formas de reinserção social dos residentes.

Ainda sobre essa questão, quatro profissionais da enfermaria feminina e dois da masculina entendem que tais atividades possibilitam diminuir o estigma social existente em torno da loucura na sociedade. Em numero menor - dois técnicos da ala feminina e um da masculina - são os profissionais que percebem esse trabalho, unicamente, como um momento de lazer e saída da rotina. Além disso, em contraponto, dentre os 22 entrevistados na enfermaria feminina, dois não vêem possíveis efeitos dessas atividades nas vidas das residentes.

No que se refere à desinstitucionalização, três profissionais que trabalham com as mulheres e um que trabalha com os homens mostraram-se desfavoráveis a esse processo, enquanto que 18 e 14, respectivamente, colocaram-se a favor. Somente um profissional da enfermaria feminina trata da questão como sendo relativa, com a justificativa de que pode funcionar apenas com algumas pessoas.

Quando se referindo a como deveria se dar a saída do hospital e o retorno ao convívio em sociedade, a resposta mais frequente foi o encaminhamento dos moradores do hospital aos Serviços Residenciais Terapêuticos (SRT) - citado por oito entrevistados da ala feminina e seis da masculina. Suscitou-se até mesmo a necessidade de prezar pelo intercâmbio de informações entre os que serão e os que já são cuidadores (tanto em outros SRT, como no hospital). Profissionais das duas enfermarias - cinco da feminina e três da masculina também mencionaram a importância da elaboração de um projeto que respeitasse as singularidades de cada um dos residentes.

Sete profissionais de cada uma das enfermarias acham que é possível que essas pessoas voltem a viver em sociedade, desde que os devidos serviços e cuidadores (família ou técnicos) os acompanhem e dê suporte. Da enfermaria masculina, três acham necessária a existência de um modelo de SRT mais complexo para acolher alguns dos residentes de longa permanência do hospital.

Quando perguntados sobre que atividades poderiam contribuir para o processo de reinserção social dos moradores de longa permanência, a resposta mais frequente em ambos os grupos de profissionais foi relativa ao aumento da ocorrência das atividades realizadas fora do hospital, voltadas para o contato com a comunidade - abrangendo dez profissionais na ala feminina 
e oito na masculina. A segunda mais citada também foi uma resposta em comum a esses dois grupos (oito e quatro profissionais, respectivamente) e diz respeito à continuidade e ao aprimoramento das atividades feitas no setor de Terapia Ocupacional que se aproximam de exercícios que cotidianamente se costuma realizar na vida (como lavar pratos, conforme citado nas entrevistas). Além disso, os dois conjuntos de técnicos apontam o trabalho em equipe como facilitadores do processo.

Outro profissional falou da necessidade de trabalhar as ideias e práticas envolvidas no processo de desinstitucionalização não só com os moradores, mas também com os cuidadores. Nesse mesmo sentido, um técnico da ala masculina citou o investimento em atividades voltadas para a desinstitucionalização dentro das instituições asilares também como algo que poderia contribuir. Nesse setor também foi apontada a necessidade de discutir e divulgar o tema na mídia e a criação de mecanismos de geração de renda voltados para os residentes.

\section{As Oficinas Corporais}

Como já mencionado, as práticas corporais desenvolvidas no hospital tiveram como foco os profissionais da instituição. Os participantes incluíram técnicos das duas enfermarias, em uma mesma oficina, e, por isso, houve situações em que algumas das pessoas não se conheciam. Não houve alguém ou um grupo de pessoas que tenha participado regularmente de todos os encontros.

Cada oficina pautou-se em temáticas principais, como cuidado, confiança no outro, contato com o outro, equilíbrio, percepção e conhecimento corporal. Ao final de cada encontro, as observações suscitadas pelas atividades foram, geralmente, associadas pelos participantes a situações do cotidiano de trabalho no hospital, quando expressaram a "descoberta" do corpo como algo de si que estavam negligenciando e indicaram necessidades de cuidado para si mesmos enquanto profissionais. Além disso, nesse momento expressaram como perceberam seus corpos enrijecidos e atribuíram isso ao cotidiano institucional "pesado".

De modo geral, visando ao cuidado e à consciência corporal por meio das atividades, buscou-se despertar possibilidades de dispor e movimentar o corpo, diferenciadas das que costumeiramente se aplicam ao ambiente de trabalho ou mesmo à vida cotidiana. Como resposta do grupo, no geral, fora constatada dificuldade dos participantes em concentrar-se nas atividades propostas (ao não manter os olhos fechados, por exemplo), em confiar uns nos outros nas atividades e em realizar movimentos incomuns, seja pelo imediatismo com que surgiam os movimentos já mecânicos, seja pela fragmentação corporal (expressa pela dificuldade em trabalhar com mais de uma região corporal simultaneamente).

As atividades realizadas foram ou de cunho cooperativo ou individual, não havendo proposta de competição. Numa atividade em que se propôs o trabalho em equipe, os participantes comentaram, ao final, sobre a importância da cooperação, do respeito e da paciência no trabalho em grupo e perceberam como realizam poucas atividades de trabalho verdadeiramente em equipe a partir desses princípios que consideraram relevantes. Assim, o incentivo a trabalhos cooperativos entre eles foi visto como uma necessidade e que ajudaria a "desinstitucionalizar" o trabalho deles (termo utilizado por um dos profissionais).

Ressalte-se, por fim, que mesmo o momento das oficinas ser de uma hora semanal e estas serem fixada desde o princípio, a inserção desse momento na organização dos horários dos técnicos configurou-se como uma dificuldade, por chocar, muitas vezes, com o período das escalas de trabalho.

\section{Discussão}

\section{O Lugar do Corpo e da Desinstitucionalização no Contexto do Hospital}

O manicômio é uma instituição total e, por seu posto, é gerido por normas rígidas, relações hierárquicas de poder e controle e centrada na realização de um tipo específico de atividade - seja ela corretiva, educativa, terapêutica, dentre outras (Goffman, 2008). Além disso, ele concentra, no mesmo espaço institucional, a execução da atividade citada e da moradia e lazer das pessoas que são alvo desse trabalho. Ou seja, pressupõe-se a separação da sociedade mais ampla para fins de condução de vida de maneira formalmente administrada, para que seja efetiva a absorção, por essas vidas, das regras que regem a instituição.

A partir das observações e entrevistas, registrou-se a marca da autonomia e independência comprometidas, além da perda de vínculos sociais - esperáveis, considerando a submissão às ordens institucionais e à limitação espaço-temporal e relacional do lugar em que vivem, sobretudo no que se refere às mulheres internas. Em Goffman (2008), a perda da autonomia é associada à constante submissão pessoal diante da realização de atividades básicas ou secundárias, bem como à 
interferência dos que trabalham na instituição sobre as ações dos internados. Nesse mesmo sentido, Basaglia (1967/2005), ao tomar o corpo institucionalizado da psiquiatria como objeto de estudo, considera que a própria organização hospitalar vai sendo progressivamente incorporada pelos internos até se converter na expressão de sua própria doença. Em suas palavras: "Dessa forma, a doença se transforma gradualmente naquilo que a instituição psiquiátrica é, e a instituição psiquiátrica encontra no doente (...) a confirmação da validade de seus princípios" (Basaglia, 1967/2005, p. 76).

Ao avançar nas reflexões sobre o corpo institucionalizado, encontramos também a institucionalização do corpo dos profissionais que "operam" a instituição psiquiátrica, como ficou evidente nas oficinas corporais. As características do corpo dos profissionais parecem reproduzir a própria organização hospitalar em sua rigidez, hierarquia, fragmentação e mecanização dos movimentos. As proposições de exercícios e práticas que envolvessem maior flexibilidade, confiança no outro, articulação com os outros participantes e também coordenação de diferentes grupos musculares foram recebidas sempre com muita resistência.

Segundo Amarante (1996), baseado nas reflexões de Basaglia, o louco, expropriado de seus direitos, de sua família, de sua comunidade de origem e do convívio com a sociedade, deve ter na cidade "o espaço real de sua reabilitação, ou melhor, de sua reabilitação social, ou, melhor ainda, dos processos de validação social dos sujeitos" (p. 97). A proposta basagliana passa, então, pela necessidade do encontro entre a loucura e a cidade, entendendo esta como território, ou seja, como uma "força viva de relações concretas e imaginárias que as pessoas estabelecem entre si, com os objetos, com a cultura e com as relações que se dinamizam e se transformam" (Amarante, 1995, p. 145). Aqui interessa observar como isso foi apontado pelos entrevistados como uma necessidade do processo de desinstitucionalização para os internos. No entanto, também para eles (profissionais), as atividades "de fora", que rompiam de alguma maneira com o cotidiano e a rotina hospitalar foram colocadas como importantes para o trabalho e podemos também refletir como a possibilidade dos profissionais experimentarem seus corpos "fora" da rotina institucional em sua rigidez e previsibilidade, pode contribuir para a inovação em suas práticas de cuidado junto aos moradores, fazendo com que eles ganhem também recursos para realizar o trabalho de desinstitucionalização.
Nesse sentido, ao experimentar novas práticas corporais, os profissionais voltam o olhar sobre si mesmos como corpos em institucionalização, e podem questionar esse processo, o que se constitui como uma necessidade no trabalho junto aos moradores. Assim, interessa questionar até que ponto os trabalhos elaborados são coerentes com as necessidades e anseios dos moradores e com o processo de desinstitucionalização. Qual o sentido das atividades disponibilizadas? O que elas de fato puderam produzir?

Em consonância com os dados sobre a participação, os técnicos da enfermaria masculina demonstraram um maior reconhecimento sobre os benefícios das atividades voltadas para a desinstitucionalização do que os da ala feminina. Essa aposta em bons resultados por meio das atividades extramuros pode ser encarada tanto como causa como consequência de uma realização mais frequente desse trabalho junto aos homens.

Importante aqui considerar esta diferença as características das mulheres em situação de institucionalização. Apesar de o número de mulheres ser menor, os profissionais afirmam que elas ficam mais tempo internadas e têm menos autonomia que os homens, também reproduzindo no cotidiano institucional as questões vivenciadas pelo gênero feminino em nossa sociedade e as dificuldades dos próprios profissionais em romper com a institucionalização dos gênero que coloca as mulheres como "mais reclusas" que os homens na vida social em geral, como indicam Pegoraro e Caldano (2008) em seu estudo sobre história da loucura em mulheres.

Mas quando o foco é a desinstitucionalização, as propostas de atividades não devem ser pensadas apenas para os moradores do hospital. Os cuidadores, igualmente, permanecem parte de seus dias na instituição e, dessa forma, também vivem e incorporam as normas e os princípios que a regem. Assim, ações nesse sentido possibilitam que se preste um melhor atendimento aos pacientes, podendo também serem promotoras de qualidade de vida para o cuidador.

\section{A Instituição e seus Muros}

A inserção das oficinas corporais na organização do hospital esbarrou em dificuldades e desafios. Mesmo tendo sido firmado horário, duração e datas desde o início dos encontros, a participação de poucos trabalhadores revelou uma dificuldade em conciliar as escalas de trabalho com o momento das oficinas: muitos dos técnicos que estavam no hospital encontravam-se em horário de expediente e, portanto, não compareciam 
à atividade por nós proposta. Isso sugere uma limitação do hospital como instituição de cuidado, visto que, diante da possibilidade de se realizar um trabalho com os técnicos diferente dos de suas especialidades profissionais, as escalas de expediente foram majoritariamente escolhidas e revelou-se pouca reflexibilização na execução das atividades.

Entretanto, há que se considerar que o próprio cunho corporal das atividades propostas pode ter servido como inibidor da participação. Isso porque elas abrangem a possibilidade de o profissional submeter-se a movimentos que possam estar sujeitos à censura - por motivos diversos, como por parecerem inusitadas diante de aparição social e isso ser objeto de controle na panoptia institucional que assume uma lógica disciplinar de funcionamento (Foucault, 2002a).

Os profissionais encararam as oficinas como um trabalho de promoção do bem-estar, de "relaxamento", para citar a fala de alguns. Elas foram associadas a momentos de "refúgio do trabalho", em que se buscava um distanciamento das obrigações e dos pacientes, um período exclusivo para os técnicos. Assim, além de criar esse "afastamento" das atividades rotineiras, as práticas corporais parecem ter funcionado como "ilhas" de respiro institucional para os profissionais:

Toda instituição total pode ser vista como uma espécie de mar morto, em que aparecem pequenas ilhas de atividades vivas e atraentes. Essa atividade pode ajudar o indivíduo a suportar a tensão psicológica (...). No entanto, precisamente na insuficiência de tais atividades, podemos encontrar um importante efeito da privação das instituições totais (Goffman, 2008, p.66)

As oficinas enquanto essas "ilhas" também se converteram em espaços de reflexão e crítica sobre as relações entre eles no cotidiano de trabalho, ainda que o explícito questionamento ao manicômio não tenha surgido. Por isso e por ter sido uma ação pontual, não podemos dizer que foram espaços efetivos de desinstitucionalização como desconstrução de saberes e práticas que sustentam o manicômio como estrutura física e como cultura. No entanto, parece haver em atividades dessa natureza a potência para ir promovendo desinstitucionalização como processo, caso tenha continuidade e se realize também fora dos muros institucionais com vinculação a projetos efetivamente antimanicomiais.

Concordamos com a ideia de Rotelli et al. (2001) de que o movimento da desinstitucionalização deva ocorrer de dentro para fora do hospital psiquiátrico.
Dessa forma, apostamos no "trabalho homeopático", em que as transformações institucionais são produzidas de dentro para fora, trabalhando-se a partir do já existente: "a desinstitucionalização é um trabalho prático de transformação que, a começar pelo manicômio, desmonta a solução institucional existente para desmontar (e remontar) o problema" (Rotelli et al., 2001, p. 29).

O entendimento de que a desinstitucionalização não se resume a desospitalização, mas a um processo complexo de desconstrução de práticas, discursos e saberes tem como um ponto de resistência o reconhecimento de si como possível entrave para o processo. Assim, remetemo-nos aos "desejos de manicômio" existentes em todos nós, os quais são desejos de identidade, fixidez, controle e normatização que nos atravessam e se fazem presentes em toda e qualquer forma de expressão que se sustente em práticas de dominação e racionalidades opressoras e fascistas (Machado \& Lavrador, citado por Alverga \& Dimenstein, 2006).

Cegos por esses "desejos de manicômio", prendemo-nos a lugares e normas instituídos e deixamos de enxergar outras possibilidades e potencialidades de vida. E estar preso a um lugar fixo requer princípios, posturas e discursos que sustentem essa estrutura.

\section{Expressão Corporal e (des)Institucionalização}

Quando pensamos nesses desejos de normatização, fixidez e racionalidade transpostos a nossos modos de ser, encontramos uma série de padrões que a sociedade classifica como normal e que devem ser seguidos por quem quiser ser assim reconhecido. Esses protótipos incluem, principalmente, comportamentos corporais que envolvem formas mecânicas e repetitivas de proceder, as quais encobrem a sensibilidade e possibilidade criativas.

Em consonância com o exposto e considerando as normas e censuras socialmente padronizadas, entendemos a preocupação com a fiscalização e com o julgamento do outro sobre o corpo como motivadores, nas oficinas realizadas, da dificuldade de concentração e de manutenção dos olhos fechados expressas por alguns. Dessa mesma forma, também podem ser percebidas as necessidades de verbalização durante as atividades, que, em seus conteúdos, trazem como que justificativas daquele que fala sobre o que está fazendo, da forma como está fazendo. Isso mostra, também, a dificuldade na compreensão quando se utilizou de outras formas, que não a palavra, para comunicar-se - por exemplo, o corpo.

Parece possível indicar esses elementos da expressão corporal como próprias da biopolítica que 
se revela na vida institucional e se afirma no corpo dos profissionais. De acordo com Foucault (2002b), a biopolítica consiste na ação do Estado de controle dos corpos individuais em sua "anatomopolítica" através de tecnologias disciplinares e de regulação, da mesma forma que controla a população através de tecnologias de massificação da vida em seus processos (nascimento, morte, doença, etc). Os saberes médicos e psicológicos participam na constituição das tecnologias biopolíticas ao criar referencias normativas de governo da vida individual e coletiva que são a todo tempo reproduzidas no cotidiano manicomial.

Conhecer o próprio corpo perpassa a compreensão das possibilidades de relações do mesmo - quer seja com o ambiente, com o outro ou consigo -, de maneira que ele seja vivido em sua integralidade, e não dicotomicamente. Dessa forma, relaciona-se a diversidade de movimentos que o corpo pode assumir e aos significados presentes neles. Tomando tal ideia como base, pode-se afirmar, no geral, a fragilidade na compreensão sobre o próprio corpo por parte dos participantes das oficinas, materializada na fragmentação corporal e na necessidade de cessar a movimentação de alguns membros para iniciar a de outros, quando fora solicitado o movimento simultâneo.

Ademais, em atividades que abarcaram o toque, este ocorreu, no geral, em regiões do corpo em que o contato é trivial, como nas mãos e braços. Ao nosso entender, isso demonstra tanto uma repercussão do mecanicismo dos movimentos como uma não abertura a relações espontâneas entre os participantes.

Esses achados indicam a captura dos corpos em suas sensibilidades e possibilidades criativas capazes de lidar com as instabilidades, as imprevisibilidades e o inusitado. São efeitos do processo de institucionalização calcados na estabilidade e previsibilidade das ações que visam "proteger" os profissionais do "contágio" pela loucura (Basaglia, 1967/2005).

Interessante perceber como precisamente esses elementos que, no interior do manicômio são negados pelas normativas e condições de trabalho que formatam certos modos de ser no corpo, são aqueles mais necessários nos processos de desinstitucionalização que exigem constante inventividade para lidar com as instabilidades, as imprevisibilidades e o inusitado que o encontro entre loucura e cidade produz, como foi possível observar em outros estudos (Amorim \&Dimenstein, 2009; Salles \& Miranda, 2016).
Nesse sentido, acreditamos na potência desinstitucionalizante do trabalho com oficinas de práticas corporais dentre outras que envolvam a construção de novas sensibilidades, ativem a criatividade e contribuam para que os profissionais desenvolvam os recursos e habilidades necessários aos desafiantes processos de desinstitucionalização da loucura e do louco, tal como indicou o trabalho de Souza, Silva, Santos, Pardo e Rigo (2010).

Entendemos que o fato de o grupo de participantes não ter sido o mesmo em todas as oficinas realizadas dificultou a possibilidade de se realizar um trabalho gradual e com produção de vínculos, visto que todas as etapas pensadas para o processo não foram vividas por cada uma das pessoas. Entretanto, acreditamos que o encontro com as práticas corporais, mesmo que de forma pontual, pôde surtir efeitos, considerando os comentários positivo obtidos ao final de cada oficina.

\section{Considerações finais}

A despeito do que conquistamos no campo da saúde mental, com a sanção da Lei n. 10.216, de 2001, que definiu novos rumos para a Reforma Psiquiátrica no Brasil, encontramos ainda fortalecida uma cultura que sustenta o manicômio e as relações, os saberes e as práticas que o constituem. Essas vigoram mais fortemente nos hospitais psiquiátricos, como aquele em que nos inserimos para a pesquisa. Muitos desses aspectos estão materializados na disposição física do espaço, no entendimento sobre cada trabalho e atividade na instituição, na forma de relacionar-se com os outros e, sobretudo, nos corpos dos profissionais, como foi possível constatar nas oficinas.

De modo geral, foi possível perceber os efeitos dos processos de institucionalização nos modos de perceber o corpo e nas expressões corporais produzidas a partir das proposições de práticas nas oficinas. As dificuldades e resistências por parte dos profissionais em realizar atividades que diferissem daquelas de seu cotidiano e envolvessem desequilíbrio, desestabilização, instabilidades, articulação de muitos grupos musculares, são algumas evidências.

Por outro lado, foi possível constatar nas entrevistas, observações e oficinas a necessidade dos profissionais realizarem atividades no "fora" institucional que produzissem certos respiros e aberturas dentro da rigidez da organização hospitalar, seja como forma de cuidar dos cuidadores, seja como espaços para desenvolvimento 
de recursos e habilidades necessárias ao processo de desinstitucionalização com o qual estão envolvidos.

Percebemos ser possível a desconstrução dessa cultura pelas vias do corpo, das práticas corporais propostas, instigando as reflexões, os desejos e a sensibilidade possíveis de aflorar a partir da expressão do mesmo, de diversas formas, sendo estas maneiras encontradas quando se restaura a criatividade e a espontaneidade corporal. Resgatar essa sensibilidade repercute nas formas de ser e agir, podendo despertar novos devires. As reflexões suscitadas a partir das oficinas corporais apontaram para esse sentido, ainda que o caráter pontual da ação realizada não nos permita falar que contribuímos efetivamente para a desinstitucionalização das práticas e saberes manicomiais.

Assim, concluímos afirmando a necessidade de atividades que envolvam a construção de novas sensibilidades, ativem a criatividade e contribuam para que os profissionais desenvolvam os recursos e habilidades para lidar com os imprevisível, o inusitado, as instabilidades e as novidades que o encontro entre louco e cidade, loucura e cidadania produzem, convocando a contínua construção de práticas nos desafiantes processos de desinstitucionalização.

\section{Referências}

Alverga, A. R., \& Dimenstein, M. D. A. (2006). Reforma Psiquiátrica e os desafios da desinstitucionalização da loucura. Interface Comunicação, Saúde, Educação, 10(20), 299-316. doi: 10.1590/ S1414-32832006000200003

Amarante, P. (1995). Loucos pela vida - a trajetória da reforma psiquiátrica no Brasil. Rio de janeiro: SDE/ENSP.

Amarante, P. (1996). O homem e a serpente: outras histórias para a loucura e a psiquiatria. Rio de Janeiro: Fiocruz.

Amarante, P. (2007). Saúde mental e atenção psicossocial. Rio de janeiro: Editora Fiocruz.

Amorim, A. K. A., \& Dimenstein, M. (2009). Loucura e cidade: cenas biopolíticas e incursões (des) institucionalizantes. Fractal: Revista de Psicologia, 21(2), 319-335.

Bardin, L. (2004). Análise de conteúdo. Porto/Portugal: Edições 70.

Basaglia, F. (2005). Corpo e instituição: considerações antropológicas e psicopatológicas em psiquiatria institucional. Rio de Janeiro: Garamond. (Texto original publicado em 1967)

Brasil, Ministério da Saúde, Secretaria-Executiva, Secretaria de Atenção à Saúde. (2004). Legislação em Saúde Mental: 19902004. (5 ed. Ampliada). Brasília: Ministério da Saúde.

Caprara, A., \& Landim, L. P. (2008). Etnografia: usos, potencialidades e limites na pesquisa em saúde. Interface-Comunicação,
Saúde, Educação, 12(25), 363-76. doi: 10.1590/ S1414-32832008000200011

Costa, V. M. (2011). Corpo e história. Revista Ecos, 10(1), 245-258. Recuperado de http://periodicos.unemat.br/index.php/ecos/article/ view/777/821

Foucault, M. (2002a). Vigiar e Punir. (28 ed.). Petrópolis: Vozes.

Foucault, M. (2002b). Em defesa da sociedade: curso no Collège de France (1975-1976). São Paulo, SP: Martins Fontes.

Goffman, E. (2008). Manicômios, prisões e conventos (8 ${ }^{\mathrm{a}}$ ed.). São Paulo: Perspectiva.

Gonçalves, S., Fagundes, P., Lovisi, G., \& Lima, L. A. (2001). Avaliação das limitações no comportamento social em pacientes psiquiátricos de longa permanência. Ciência \& Saúde Coletiva, 6(1),105-113. doi: 10.1590/S1413-81232001000100009

González-Rey, F. L. (2002). Pesquisa qualitativa em psicologia: caminhos e desafios. São Paulo: Cengage Learning.

Lei no 10.216, de 6 de abril de 2001 (2001). Dispõe sobre a proteção e os direitos das pessoas portadoras de transtornos mentais e redireciona o modelo assistencial em saúde mental. Brasília, DF: Casa Civil da Presidência da República do Brasil.

Medeiros, S. M., \& Guimarães, J. (2002). Cidadania e Saúde mental no Brasil: Contribuição ao debate. Ciência \& Saúde Coletiva, 7(3), 571-579. doi: 10.1590/S1413-81232002000300014

Mendes, M. I. B., \& Nóbrega, T. P. (2009). Cultura de Movimento: reflexões a partir da relação entre corpo, natureza e cultura. Pensar a Prática, 12(2), 1-10. doi: 10.5216/rpp.v12i2.6135

Moreira, M. I. B., \& Castro-Silva, C. R. (2011). Residências terapêuticas e comunidade: a construção de novas práticas antimanicomiais. Psicologia \& Sociedade, 23(3), 545-553. doi: 10.1590/ S0102-71822011000300012

Paulon, S. M. (2005). A análise de implicação como ferramenta na pesquisa-intervenção. Psicologia \& Sociedade, 17(3), 18-25. doi: 10.1590/S0102-71822005000300003

Pegoraro, R. F., \& Caldana, R. H. L. (2008). Mulheres, loucura e cuidado: a condiçãoo da mulher na provisão e demanda por cuidados em saúde mental. Saúde e Sociedade, 17 (2), 82-94. doi: 10.1590/ S0104-12902008000200009

Rodrigues, D. (Org.). (2008). Os valores e as atividades corporais. São Paulo: Summus.

Rotelli, F., Leonardis, O., \& Mauri, D. (2001). Desinstitucionalização, uma outra via. In F. Nicácio (Org.), Desinstitucionalização (pp. 89-99, $2^{a}$ ed.). São Paulo: Hucitec.

Salles, A. C. R., \& Miranda, L. (2016). Desvincular-se do manicômio, apropriar-se da vida: persistentes desafios da desinstitucionalização. Psicologia \& Sociedade, 28(2), 369-379. doi: 10.1590/1807-03102016v28n2p369

Sant'Anna, D. B. (Org.). (1995). Políticas do corpo. São Paulo: Estação Liberdade.

Souza, T. S., Silva, M. R., Santos, D. P., Pardo, E., \& Rigo, L. C. (2010). Educação física, corpo e saúde mental: uma experiência em um centro de atenção psicossocial (CAPS). Fiep Bulletin, 80(1). Recuperado de http://www.fiepbulletin.net/index.php/fiepbulletin/ article/view/983 
Ana Karenina de Melo Arraes Amorim, Doutora em Psicologia Social pela Universidade Federal do Rio Grande do Norte (UFRN), é Professora Adjunta IV do Departamento de Psicologia da Universidade Federal do Rio Grande do Norte (UFRN).

Endereço para correspondência: Rua Ismael Pereira da Silva, 1774, apto1501, torre 2, Capim Macio - CEP: 59.082-000. Natal/RN

E-mail: akarraes@gmail.com

Maria Aparecida Dias, Doutora em Educação pela Universidade Federal do Rio Grande do Norte (UFRN), é Professora Adjunta IV do Departamento de Educação Física da Universidade Federal do Rio

Grande do Norte (UFRN).

E-mail: cidaufrn@gmail.com

Mackson Luiz Fernandes da Costa, Mestre em Educação Física pela Universidade Federal do Rio Grande do Norte (UFRN), é Professor do Instituto Federal do Rio Grande do Norte (IFRN). E-mail: macksonluiz@gmail.com

Allana de Carvalho Araújo, Graduada em Psicologia pela Universidade

Federal do Rio Grande do Norte (UFRN), Mestranda no Programa de Pós-Graduação em Psicologia da Universidade Federal do Rio Grande do

Norte (UFRN).

E-mail: allanaraujo_@hotmail.com

Deyze da Silva Ferreira, Especialista em Psicologia da Saúde, Desenvolvimento e Hospitalização pela Universidade Federal do Rio Grande do Norte (UFRN), é Professora Substituta do Departamento de Fundamentos e Políticas da Educação do Centro de Educação da Universidade Federal do Rio Grande do Norte (UFRN).

E-mails: deyze.silfer@gmail.com e/ou deyze_silfer@hotmail.com

Recebido em 16.Ago.15 Revisado em 05.Out.16

Aceito em 19.Dez.16 